\title{
Relationship amongst teratozoospermia, seminal oxidative stress and male infertility
}

\author{
Ashok Agarwal', Eva Tvrda and Rakesh Sharma
}

\begin{abstract}
Background: Spermatozoa morphology is an important and complex characteristic of the fertilization capacity of male germ cells. Morphological abnormalities have been observed to be accompanied by reactive oxygen species (ROS) overproduction and further damage to spermatozoa, ultimately leading to infertility. Therefore, this study aimed to examine the relationship between seminal ROS production and sperm morphology in infertile teratozoospermic patients as well as in healthy men of proven and unproven fertility.

Methods: Semen samples were collected from 79 patients classified as teratozoospermic and 56 healthy donors (control). Standard semen analysis was performed and spermatozoa morphology was assessed according to the WHO 2010 guidelines. Seminal ROS was measured by chemiluminescence assay. Receiver operating characteristic (ROC) curves were generated, and sensitivity, specificity, cutoff value and area under curve (AUC) were determined.

Results: Sperm morphology was significantly poor in the Teratozoospermic Group compared with the 3 Donor Groups ( $P<0.05)$. Significantly higher levels of ROS (RLU/sec $/ 10^{6}$ sperm) were seen in the Teratozoospermic group (145.4 (41.5; 555.4) compared to the Donor Groups: All Donors (64.8 (21.1; 198.2), Proven Donors (58.8 (14.2; 79.2) and Proven Donors $<2$ years $(58.8$ (14.2; 79.2) $(P<0.05)$. ROS correlated negatively with sperm concentration in the All Donor group ( $r=-0.354 ; P=0.021)$ as well as in the Teratozospermic group $(r-0.356 ; P=0.002)$. Using ROC analysis, we established the cutoff values for concentration, morphology and ROS.

Conclusions: The incidence of teratozoospermia may be directly related to the overproduction of seminal ROS. Therefore, besides sperm concentration and motility, spermatozoa morphology should receive an equally important consideration in the overall assessment of male fertility.
\end{abstract}

Keywords: Spermatozoa, Reactive oxygen species, Morphology, Teratozoospermia, Male infertility

\section{Background}

Increasing fertilization incompetence has become a major concern for males and females of reproductive age. As male factor is thought to contribute to approximately $40 \%$ of all infertility cases, an accurate semen analysis should be the keystone of the assessment of male fertilization potential $[1,2]$.

Sperm count and sperm motility are typically the first diagnostic markers to be evaluated when studying semen quality. Morphology of the sperm cell is an underrated semen parameter, mainly because of the lack of a commonly accepted evaluation method as well as a general cut-off value [2-4]. Nevertheless, the morphologic characteristics of

\footnotetext{
* Correspondence: agarwaa@ccf.org

Center for Reproductive Medicine, Glickman Urological and Kidney Institute, Cleveland Clinic, Cleveland, Ohio 44195, USA
}

the sperm cell are the outcome of highly complex cellular modifications occurring during spermatogenesis $[3,5,6]$. The resulting percentage of abnormal spermatozoa as well as specific structural abnormalities may serve as an indicator of a defective mechanism related to spermatozoa production and/or maturation [1] and is a valuable predictor of spontaneous pregnancies and fertilization success in assisted reproductive technology (ART) [7-9]. Furthermore, abnormal spermatozoa morphology has been linked not only to a decrease of traditional parameters of semen quality [10-12] but also to an increase in contemporary markers of sperm damage, such as DNA fragmentation $[1,2]$ or reactive oxygen species (ROS) overproduction $[13,14]$.

A common origin of both pathological spermatozoa and ROS may be found within the sperm membrane remodeling 
during spermatogenesis. Due to failures in the process, such as abnormal head-tail attachments, incomplete acrosomal development or alterations in the sperm cytoskeleton [15], spermatozoa exhibit cytoplasmic residues leading to the creation of both morphologically abnormal structures as well ROS [16]. Pathological spermatozoa, together with leukocytes, are considered to be the primary source of free radicals in semen $[14,17,18]$. Additionally, ROS overproduction has been linked to oxidative damage of the poorly protected sperm cell. The polyunsaturated fatty acids (PUFA), present in large quantities in the cytoplasmic membrane of spermatozoa, are the primary target for deleterious peroxidation, which leads to a decreased membrane fluidity and further structural defects of the sperm cell $[19,20]$.

Although several studies have highlighted an association between spermatozoa morphology and ROS present in semen $[16,21,22]$, the exact mechanism linking both the abnormal sperm morphological forms and the oxidative balance within the sperm cell have not been investigated. Therefore, in this study, we examined the relationship between seminal ROS production and sperm morphology in infertile teratozoospermic patients as well as in healthy men of proven and unproven fertility. The results may confirm the complex biological relationship between teratozoospermia and oxidative stress and possibly help to explain the causes of male infertility in some men.

\section{Methods}

Following approval from the Cleveland Clinic Institutional Review Board (IRB), 135 subjects were enrolled in the study: 56 healthy male volunteers and 79 patients diagnosed with teratozoospermia (percentage of spermatozoa with $<4 \%$ normal morphology).

The inclusion criteria for the infertile patients were as follows: all subjects attended the male infertility clinic for fertility issues. All of these men were evaluated for proven male-factor infertility as assessed the male infertility specialist. All of them underwent history, physical and laboratory evaluation. None of them had female factor infertility in their partners. Our exclusion criteria were: azoospermia, incomplete semen analysis results or inadequate semen sample for ROS measurement.

The donors were healthy males, 20 - 35 years old whose semen samples fulfilled the criteria established by the WHO 2010 guidelines for semen analysis i.e. normal semen parameters [23]. Of the 56 donors, 28/56 (50\%) were of proven fertility (having established a successful pregnancy in the past), and 16/56 (28.6\%) had initiated a pregnancy in the past 2 years.

The inclusion criteria for the All Donor group were: 1 ) normal semen parameters; 2) no sexually transmitted infections; 3) no recreational drug use, and 4) may or may not have initiated a pregnancy in the past. The Proven
Donor group $(\mathrm{n}=28)$ included men who had initiated a pregnancy at some point. The inclusion criteria were: 1) normal semen parameters; 2) no sexually transmitted infections; 3) no recreational drug use and 4) Initiated a pregnancy in the past. The third donor group (Proven Donors $<2$ years $)(n=12)$ included men who had initiated a pregnancy in the past two years. The Inclusion criteria were: 1) normal semen parameters; 2) no sexually transmitted infections; 3) no recreational drug use and 4) initiated a pregnancy within the past 2 years. The exclusion criteria for the donors were the following: azoospermia, incomplete semen analysis results or inadequate semen sample for measurement of ROS.

\section{Semen analysis}

Semen samples were collected by masturbation after 2-3 days of sexual abstinence. After liquefaction, a complete semen analysis was performed to evaluate the sperm parameters according to the World Health Organization (WHO) guidelines [23]. Sperm concentration and percentage motility analysis were done using a MicroCell counting chamber (Vitrolife, San Diego, California).

\section{Measurement of white blood cells}

The presence of peroxidase positive leukocytes (neutrophils and macrophages) in semen was assessed by a myeloperoxidase- staining test. $20 \mu \mathrm{L}$ of liquefied semen specimen was mixed well with $20 \mu \mathrm{L}$ of phosphatebuffered saline (PBS) (pH 7.0) and $40 \mu \mathrm{L}$ of benzidine solution. The mixture was allowed to sit at room temperature for 5 minutes. Peroxidase positive leukocytes that stained brown were counted by a Makler counting chamber (Sefi Medical, Haifa, Israel) under a bright-field objective (magnification, $\times 20)$. The results after correction for dilution were recorded as $\times 10^{6}$ peroxidase-positive leukocytes $/ \mathrm{mL}$ of semen. A seminal leukocyte concentration of $\leq 1 \times$ $10^{6} \mathrm{WBC} / \mathrm{mL}$ was considered normal [23].

\section{Assessment of sperm morphology}

Thin smears of the well-mixed ejaculated semen were prepared in duplicate by placing $2-5 \mu \mathrm{L}$ (depending on the sperm concentration) on clean slides. After air drying, the slides were stained using Diff-Quik kit (Baxter Healthcare Corporation, Inc., McGaw Park, IL) and graded on the basis of the Kruger's Strict criteria and cutoff value established by WHO 2010 guideline [23]. A total of 100 spermatozoa were scored per slide using bright field illumination and an oil immersion objective with a total magnification of $\times 2000$. At least ten high-power fields selected at random from different areas of the slide were examined.

\section{Measurement of reactive oxygen species}

ROS levels in seminal ejaculates were measured by chemiluminescence assay using luminol (5-amino-2, 3- dihydro-1, 
4-phthalazinedione; Sigma, St Louis, MO) as the probe. The test samples consisted of luminol $(10 \mu \mathrm{L}, 5 \mathrm{mM})$ and $400 \mu \mathrm{L}$ of semen. Negative controls were prepared by replacing the sperm suspension with $400 \mu \mathrm{L}$ phosphate buffered saline. Positive control included $400 \mu \mathrm{L}$ of PBS and $50 \mu \mathrm{L}$ of hydrogen peroxide $(30 \% ; 8.8 \mathrm{M})$ in triplicates. Chemiluminescence was measured for 15 min using a Berthold luminometer (Autolumat Plus 953, Oakridge, $\mathrm{TN})$. The results were expressed as relative light units (RLU)/sec $/ 10^{6}$ sperm [24].

\section{Statistical analysis}

The data were analyzed using inbuilt functions within the Statistical Package for Social Science (SPSS UK Ltd., Chertsey, Surrey, UK). Summary statistics are presented as mean and standard deviation (SD). Univariate comparison of continuous variables among the groups was performed with the Kruskal-Wallis test. Simultaneous multiple pairwise comparisons among groups were performed with the Conover-Inman test, which is simply Fisher's least significance difference method performed on ranks. Spearman's rank correlation test was used to provide a distribution-free test of independence between sperm ROS production and sperm attributes. All hypothesis testing was two-tailed; $\mathrm{P}<0.05$ was considered statistically significant. Forward stepwise logistic regression analysis was used to identify a suitable model predicting high sperm ROS production.

\section{Results}

\section{Semen parameters}

Tables 1, 2 and 3 represent the sperm parameters in three healthy donor groups (unproven fertility, any proven fertility, and proven fertility within the previous 2 years) as compared to the teratozoospermic patients. While the spermatozoa concentration was not significantly different between the patients and the donors, a significant ( $\mathrm{P}$ $<0.05)$ decrease in the seminal volume was observed in the Teratozoospermic Patients $(3.27 \pm 1.62 \mathrm{~mL})$ as compared with the Proven Donors $(4.24 \pm 2.13 \mathrm{~mL})$ and Proven Donors $<2$ years $(5.03 \pm 2.22 \mathrm{~mL})$. Spermatozoa motility was higher in the Teratozoospermic group (57.66 $\pm 12.33 \%)$ compared with both Proven Donors (50.85 $\pm 13.52 \%)$ and Proven Donors $<2$ years $(49.88 \pm 8.68 \%)$.

The highest percentage of morphologically normal spermatozoa was seen in Proven Donors followed by All Donors (Tables 1, 2, 3). Significantly lower percentages of morphologically normal spermatozoa were seen in the Teratozoospermic group $(1.52 \pm 1.12 \%)$ when compared to all three Donor groups $(\mathrm{P}<0.05)$ (Tables $1,2,3)$.

Sperm morphology was positively correlated with concentration in Donor groups $(\mathrm{P}=0.009 ; \mathrm{P}=0.037$ and $\mathrm{P}=004$, respectively). Similarly, normal morphology was correlated with motility in All Donors $(\mathrm{P}=0.001)$ and Proven Donors $(\mathrm{P}=0.032)$. Furthermore, a significant correlation was found between spermatozoa morphology and semen volume in Teratozoospermic Patients $(\mathrm{P}=0.044)$ (Table 4).

The sensitivity, specificity, cutoff value and area under curve (AUC) for the three donor groups and teratozoospermic patients are shown in Tables 1, 2, 3. Sperm morphology showed high specificity and AUC. The cutoff values for concentration were similar in the 3 Donor groups $\left(41.7,41.75\right.$ and $\left.41.75 \times 10^{6} / \mathrm{mL}\right)$. Morphology also had a similar cutoff value of $3.5 \%$ in the 3 Donor groups and Teratozoospermic group.

\section{ROS production}

All the Donor groups were characterized by normal ROS levels, as shown in Tables 1, 2, 3 as well as Figure 1. The lowest ROS values (median $\left(25^{\text {th }}, 75^{\text {th }}\right.$ percentile) were detected in proven donors $<2$ years $(58.8(14.2 ; 79.2)$ RLU/ $\mathrm{sec} / 10^{6}$ sperm). The highest ROS production was recorded in the Teratozoospermic patients group (145.4 (41.5; 555.4) $\mathrm{RLU} / \mathrm{sec} / 10^{6}$ sperm), $(\mathrm{P}<0.05)$ in comparison with all donor groups. Furthermore the ROS production was negatively correlated with the spermatozoa concentration in All Donors $(\mathrm{r}=-0.354 ; \mathrm{P}=0.021)$ as well as Teratozoospermic Patients ( $\mathrm{r}=-0.356 ; \mathrm{P}=0.002$; Table 4).

The sensitivity, specificity, cutoff value and area under curve (AUC) for ROS in the 3 Donor groups and Teratozoospermic Patients is shown in Tables 1, 2, 3 and Figure 1. ROS showed high specificity and AUC in the Proven Donors $<2$ years and Teratozoospermic group. Sensitivity was comparable in all the groups. The cutoff value was 85.9,

Table 1 Comparison of semen parameters (mean \pm SD) in All Donors $(n=56)$ and Teratozoospermic Patients $(n=79)$

\begin{tabular}{|c|c|c|c|c|c|c|}
\hline Parameter & All donors & Teratozoospermic patients & Sensitivity (\%) & Specificity (\%) & Cutoff value & AUC value \\
\hline Volume (mL) & $3.36 \pm 2.02$ & $3.27 \pm 1.62$ & 89.7 & 23.2 & 5.0 & 0.482 \\
\hline Concentration $\left(\times 10^{6} / \mathrm{mL}\right)$ & $54.26 \pm 32.19$ & $60.64 \pm 53.58$ & 55.7 & 63.6 & 41.7 & 0.529 \\
\hline Motility (\%) & $53.70 \pm 15.00$ & $57.66 \pm 12.33$ & 25.3 & 77.8 & 45.5 & 0.400 \\
\hline Normal morphology (\%) & $6.93 \pm 3.91$ & $1.52 \pm 1.12^{*}$ & 100 & 78 & 3.5 & 0.916 \\
\hline Endtz test $(\mathrm{WBC} / \mathrm{mL})$ & $1.04 \pm 2.54$ & $0.25 \pm 0.87$ & N/A & N/A & N/A & N/A \\
\hline ROS (RLU/sec/10 sperm) & $64.8(21.1 ; 198.2)^{* *}$ & $145.4(41.5 ; 555.4)^{*} ; * *$ & 63.9 & 65.1 & 85.9 & 0.614 \\
\hline
\end{tabular}

*Significant if $\mathrm{P}<0.05{ }^{* *}$ Values are represented as median $\left(25^{\text {th }}, 75^{\text {th }}\right.$ percentile). 
Table 2 Comparison of semen parameters (mean \pm SD) in Proven Donors $(n=28)$ and Teratozoospermic Patients $(n=79)$

\begin{tabular}{|c|c|c|c|c|c|c|}
\hline Parameter & Proven donors & Teratozoospermic patients & Sensitivity (\%) & Specificity (\%) & Cutoff value & AUC \\
\hline Volume (mL) & $4.24 \pm 2.13$ & $3.27 \pm 1.62^{*}$ & 89.7 & 35.7 & 5.0 & 0.633 \\
\hline Concentration $\left(\times 10^{6} / \mathrm{mL}\right)$ & $60.07 \pm 33.44$ & $60.64 \pm 53.58$ & 55.7 & 71.4 & 41.7 & 0.578 \\
\hline Motility (\%) & $50.85 \pm 13.52$ & $57.66 \pm 12.33^{*}$ & - & - & - & - \\
\hline Normal morphology (\%) & $7.00 \pm 4.35$ & $1.52 \pm 1.12^{*}$ & 100 & 73.7 & 3.5 & 0.913 \\
\hline Endtz test $(\mathrm{WBC} / \mathrm{mL})$ & $0.00 \pm 0.00$ & $0.25 \pm 0.87$ & N/A & N/A & N/A & N/A \\
\hline ROS (RLU/sec/10 sperm) & $75.8(33.3 ; 147.8)^{* *}$ & $145.4(41.5 ; 555.4)^{*} ;{ }^{* *}$ & 61.1 & 70.4 & 95.3 & 0.638 \\
\hline
\end{tabular}

*Significant if $\mathrm{P}<0.05$; **Values represented as median $\left(25^{\text {th }}, 75^{\text {th }}\right.$ percentile).

95.3 and $95.3 \mathrm{RLU} / \mathrm{sec} / 10^{6}$ sperm in the 3 Donor groups compared with Teratozoospermic group (Figure 1).

\section{Discussion}

Of male patients referred for fertility evaluation, $25-50 \%$ are diagnosed with idiopathic infertility $[5,6,25]$. Therefore, an accurate semen analysis plays a crucial role in the management of infertile couples and treatment options.

Ideally, the three traditional markers of semen quality (sperm count, motility, morphology) should be strongly interrelated to reflect their contribution to a successful fertilization. However, it is known now, that even if the sperm concentration or motility is good, a morphological defect may be the single most important factor reflecting the actual fertilization capacity of the sperm. (Tables 1, 2, 3) $[6,10,18,20]$. While positive correlations have been found mainly in in vivo studies, negative associations and the independent character of morphology has been also been demonstrated with fertilization success. Therefore, it is necessary to point out both - the status of morphology within the traditional semen parameters as well as its status as an individual marker. [4,25-27].

The patient population in this study presented with good sperm count and motility but poor morphology, relating to previous observations that this parameter may reflect best the actual ability of the sperm cell to successfully fertilize the oocyte [28]. In fact, strict morphology has become a significant prognostic value in assisted reproduction, as in the case of intrauterine insemination [29], in vitro fertilization (IVF) [9,30] and intracytoplasmic sperm injection (ICSI) [7,31]. Regardless of the assisted reproductive technique selected, using spermatozoa with morphological abnormalities leads to lower fertilization and pregnancy rates, as well as a higher risk of fetal DNA damage [28-31].

As traditional markers of semen quality have been defined and studied on numerous occasions, attention is driven towards new and alternative diagnostic tools, such as the evaluation of free radical production, providing explanations to the gaps between semen quality and the actual fertilization potential $[13,14,16,21]$. Our results show significant differences in the ROS levels between the Teratozoospermia group and all the Donor groups (Tables 1, 2, 3).

Overproduction of ROS and oxidative damage to the sperm cell has been acknowledged as one of the leading causes and/or secondary complications connected to the decreasing fertility potential in males [32]. Low levels of ROS (physiological levels) are needed to promote essential signaling pathways to promote spermatozoa maturation, capacitation, hyperactivation and acrosome reaction [33].

Excessive levels of ROS in the male reproductive system may be generated by two sources: immature and/or pathological spermatozoa and activated leukocytes. Leukocytes are known to generate significantly larger levels of ROS. Immature and/or pathologic spermatozoa in males with sperm abnormalities are expected to make a

Table 3 Comparison of semen parameters (mean \pm SD) in Proven Donors $<2$ years $(n=16)$ and Teratozoospermic Patients $(\mathbf{n}=\mathbf{7 9})$

\begin{tabular}{|c|c|c|c|c|c|c|}
\hline Parameter & Proven donors $<2 \mathrm{y}$ & Teratozoospermic patients & Sensitivity (\%) & Specificity (\%) & Cutoff value & AUC value \\
\hline Volume (mL) & $5.03 \pm 2.22$ & $3.27 \pm 1.62^{*}$ & 89.7 & 50 & 5.0 & 0.746 \\
\hline Concentration $\left(\times 10^{6} / \mathrm{mL}\right)$ & $61.59 \pm 23.93$ & $60.64 \pm 53.58$ & 55.7 & 87.5 & 41.7 & 0.652 \\
\hline Motility (\%) & $49.88 \pm 8.68$ & $57.66 \pm 12.33^{*}$ & 27.8 & 75 & 46.5 & 0.33 \\
\hline Normal morphology (\%) & $6.77 \pm 4.95$ & $1.52 \pm 1.12^{*}$ & 100 & 69.2 & 3.5 & 0.883 \\
\hline Endtz test $(\mathrm{WBC} / \mathrm{mL})$ & $0.00 \pm 0.00$ & $0.25 \pm 0.87$ & N/A & N/A & N/A & N/A \\
\hline ROS (RLU/sec/10 sperm) & $58.8(14.2 ; 79.2)^{* *}$ & $145.4(41.5 ; 555.4)^{*} ; * *$ & 61.1 & 93.8 & 95.3 & 0.73 \\
\hline
\end{tabular}

*Significant if $\mathrm{P}<0.05 ;{ }^{* *}$ Values are represented as median $\left(25^{\text {th }}, 75^{\text {th }}\right.$ percentile). 
Table 4 Correlations between the semen quality parameters, spermatozoa morphology and ROS production in the Donor and Teratozoospermia groups

\begin{tabular}{lccccc}
\hline Experimental group & Parameter (1) & Parameter (2) & $\mathbf{n}$ & Spearman correlation & P-value \\
\hline All Donors & Normal morphology & Concentration & 56 & 0.407 & 0.009 \\
& Normal morphology & Motile sperm & 56 & 0.508 & 0.001 \\
& ROS & Concentration & 56 & 0.354 & 0.481 \\
Proven Donors & Normal morphology & Concentration & 28 & 0.494 & 0.021 \\
& Normal morphology & Motile sperm & 28 & 0.733 & 0.032 \\
Proven Donors < 2 y & Normal morphology & Concentration & 16 & 0.346 & 0.004 \\
Teratozoospermic Patients & Motility & Concentration & 79 & 0.228 & 0.002 \\
Teratozoospermic Patients & Normal morphology & Volume & 79 & -0.356 & 0.044 \\
Teratozoospermic Patients & ROS & Concentration & 79 & & 0.002 \\
\hline
\end{tabular}

greater contribution to ROS in teratozoospermic than in normospermic males, as reflected by Gil-Guzman et al. [34] and Oborna et al. [18].

We evaluated the leukocyte concentration using the peroxidase or the Endtz test. We did not separate leukocytes from the seminal ejaculates when performing the ROS measurement. The Endtz test result in our study shows that the concentration of peroxidase-positive cells in teratozoospermic subjects was very low and nonsignificant when compared to the Donor Group. In fact, the concentration of $0.25 \pm 0.87 \times 10^{6} \mathrm{wbc} / \mathrm{mL}$ was lower than in the All Donor group $(1.04 \pm 2.54 \mathrm{wbs} / \mathrm{mL})$ although not significant and furthermore coupled with the WHO threshold of $1.0 \times 10^{6} \mathrm{wbc} / \mathrm{mL}$. We did not classify sperm abnormalities into head, mid-piece and tail abnormalities according to the WHO 1999 criteria. However, based on this observation, we assume that the ROS overproduction in the Patient Group was related primarily to the high occurrence of spermatozoa malformations. Moreover, none of the patients had elevated levels of white blood cells in the ejaculate and there the source of ROS was largely a product of increased ROS from the spermatozoa. High ROS production in the absence of leukocytes especially the granulocytes indicates the source of high ROS to be morphologically abnormal spermatozoa. This may also clarify the hypothesis that the cytoplasmic membrane could be the primary structure to be involved in morphological abnormalities of the spermatozoa. At the same time, it is the main sperm structure to be attacked by ROS [35].

Our data may supplement previous reports showing association between defective sperm function and excess cytoplasmic enzymes such as superoxide dismutase, lactic acid dehydrogenase and creatine kinase and glucose6-phosphate dehydrogenase [21,33,36-39]. These are directly involved in the oxidative balance of spermatozoa

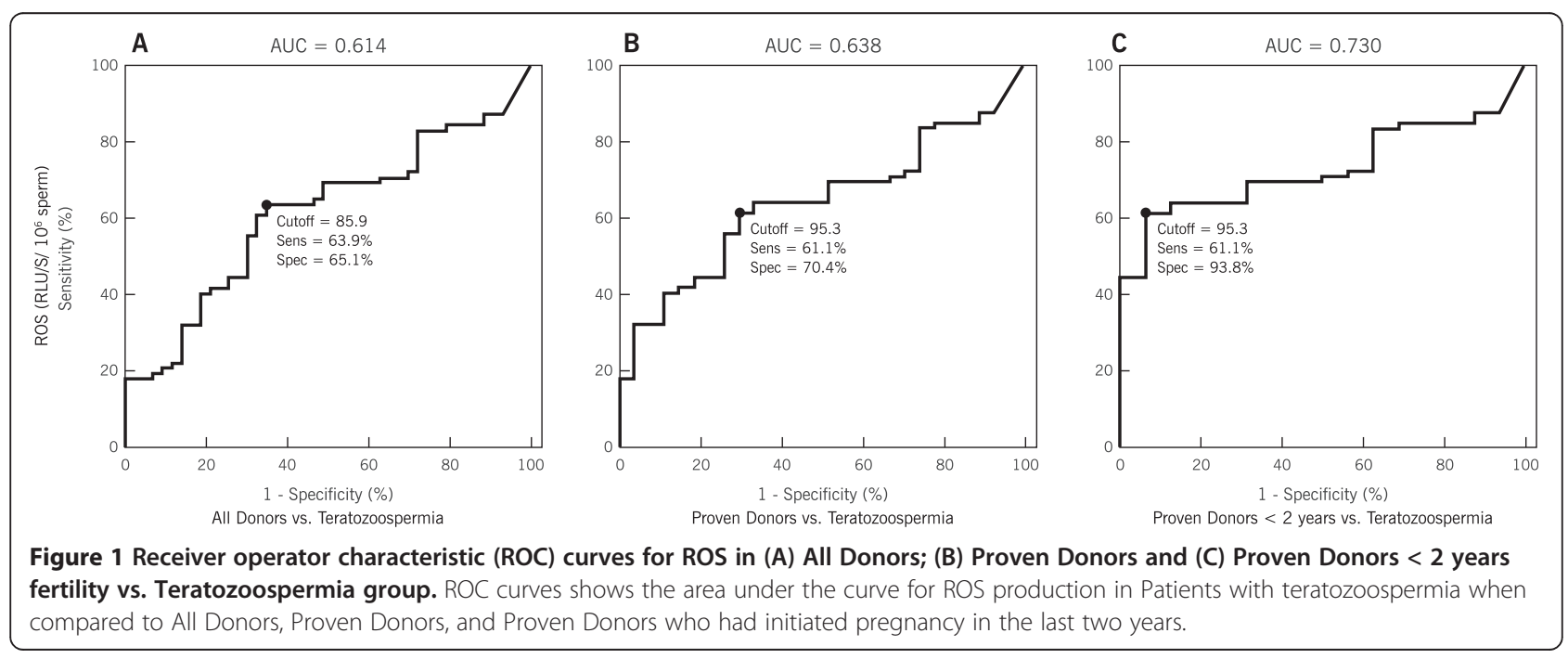


with the latter being highly interrelated with peroxidative damage to the sperm cell [40,41]. Furthermore, Ghani et al. [42] showed a significantly elevated expression of NOX5, a novel NADPH-oxidase and prime candidate for the ROS production in the acrosomal, equatorial, post-acrosomal regions of abnormal spermatozoa. Moreover, a significant positive correlation was observed between the NOX5 activity and the frequency of sperm with abnormal morphology.

Interestingly, no significant correlation was found between ROS production and spermatozoa motility, an observation contrary to a number of studies performed on ejaculates from healthy males as well as infertile patients $[17,18,21,22]$. On the other hand, Whittington et al. [43] as well as Desai et al. [44] found no correlation between the motility parameters and ROS assuming that similarly to the spermatozoa morphology, seminal ROS might be an independent marker of fertility in clinical settings. Moreover, significant connections between spermatozoa morphology and ROS were recorded in these studies proving strong interrelations between the two parameters, similar to our results (Table 4).

This study has enabled us to define the cutoff values as well as the sensitivity, specificity and the area under curve (AUC) for a variety of sperm characteristics, including morphology as well as for ROS comparing the Donor and Teratozoospermic groups. This information is important as the cutoff values may be used when identifying the different patients and donors in the future. Furthermore, we have established the cutoff values for ROS in the general donor and patient population but not specifically comparing concrete subsets of donors with unproven and proven fertility and a subset of infertile men exhibiting teratozoospermia.

Several earlier studies [45-49] have used the ROC curves to demonstrate the importance in establishing the cutoff and threshold values for different semen parameters based on clinical, rather than empiric data. Using ROC curve analysis, Ombelet et al. [45] showed that the sperm morphology was the best semen parameter with the highest prediction power (AUC $=78 \%$ ) and a cutoff value of $10 \%$. A similar threshold value was detected by Günalp et al. [46] with an AUC of 69.7\%. On the contrary, and similar to our results, Menkveld et al. [47] found a much lower cutoff value for morphology (4\%), but with a good predictive value based on an AUC of 78.2\%.

Moreover, Guzick et al. [48], using the CART analysis, was able to establish a cutoff value for spermatozoa morphology in fertile $(>12 \%)$ as well as in subfertile subjects $(<9 \%)$. Their ROC curve analysis showed that morphology had the best predictive power based on an AUC of $66 \%$.

The ROC analysis for the ROS production has been performed in a few studies only. According to Allamaneni et al. [49], the optimum ROS cutoff value to identify patients with oxidative stress in neat semen was $0.185 \times$ $10^{6} \mathrm{cpm} / 20 \times 10^{6}$ sperm, with an AUC value from $0.57-$ 0.80 . Furthermore, in the study by Desai et al. [50] the calculated ROS cutoff value to differentiate between fertile and infertile subjects was $0.0185 \times 10^{6} \mathrm{cpm} / 20 \times 10^{6}$ sperm, with the unadjusted positive predictive value of $82.4 \%$ and the negative predictive value of $77.8 \%$. Similarly, we have established the ROS cutoff value in the seminal ejaculate of $93 \mathrm{RLU} / \mathrm{sec} / 10^{6}$ sperm with a specificity of $70.4 \%$ and sensitivity of $61.4 \%$ and area under curve of $68 \%$ [24,51]. Our AUC values varied between 61.4\% and $73 \%$, proving conclusions from both manuscripts [24,51] that the ROS measurement has an important clinical relevance as a test used for infertility screening.

\section{Conclusions}

Based on the compatibility of results from our study along with previous observations, we strongly support the hypothesis that there is a direct relationship between spermatozoa morphology and oxidative balance. Disturbances in spermatozoa production and maturation may have a dramatic impact on the structural characteristics as well as free radical production in semen. Furthermore, we emphasize that spermatozoa morphology is probably the most relevant parameter of traditional semen evaluation, providing information of the fertilization potential, which in combination with modern markers of semen quality, such as ROS production, may have the best indication value of poor semen quality in the laboratory assessment of infertile men. At the same time, we suggest further comparative studies connecting the spermatozoa morphology and ROS production with further markers of semen quality, such as DNA integrity or seminal antioxidant status.

\section{Competing interests}

All authors declare no competing financial interests.

\section{Authors' contributions}

AA conceived the idea, supervised the study, and edited the article for submission. ET conducted the study and helped with the writing of manuscript, and preparation for submission. RKS helped with the review and editing of the manuscript. All authors read and approved the final manuscript.

\section{Acknowledgments}

The authors are grateful to Jeff Hammel and Amy Moore, Medical Editing for their assistance. Authors are thankful to the staff of the Andrology Center for their help in recruiting and scheduling the normal donors for this project. This study was supported by funds from the Center for Reproductive Medicine.

Received: 31 January 2014 Accepted: 18 May 2014

Published: 27 May 2014

\section{References}

1. Said TM, Agarwal A, Sharma RK, Thomas AJ Jr, Sikka SC: Impact of sperm morphology on DNA damage caused by oxidative stress induced by beta-nicotinamide adenine dinucleotide phosphate. Fertil Steril 2005, 83:95-103. 
2. Schulte RT, Ohl DA, Sigman M, Smith GD: Sperm DNA damage in male infertility: etiologies, assays, and outcomes. J Assist Reprod Genet 2010, 27:3-12.

3. Chemes EH, Rawe $\mathrm{V}$ : Sperm pathology: a step beyond descriptive morphology. Origin, characterization and fertility potential of abnormal sperm phenotypes in infertile men. Hum Reprod Update 2003, 9:405-428.

4. Menkveld R, Holleboom CA, Rhemrev JP: Measurement and significance of sperm morphology. Asian J Androl 2011, 13:59-68.

5. Skowronek MF, Alciaturi J, Casanova G, Capurro A, Montes JM, Sapiro R: Value of quantitative ultramorphological sperm analysis in infertile men. Reprod Biol 2010, 10:125-139.

6. Skowronek F, Casanova G, Alciaturi J, Capurro A, Cantu L, Montes JM, Sapiro R: DNA sperm damage correlates with nuclear ultrastructural sperm defects in teratozoospermic men. Andrologia 2012, 44:59-65.

7. Kihaile PE, Misumi J, Hirotsuru K, Kumasako Y, Kisanga RE, Utsunomiya T: Comparison of sibling oocyte outcomes after intracytoplasmic sperm injection and in vitro fertilization in severe teratozoospermic patients in the first cycle. Int J Androl 2003, 26:57-62.

8. Kellerman LM, Windt ML, Lombard CJ: The effect of sperm morphology and testicular spermatozoa on embryo quality. SAJOG 2007, 13:46-50.

9. Shu JH, Zhang B, Feng GX, Gan XY, Zhou H, Zhou L, Liu Y: Influence of sperm morphology on the outcomes and neonatal status in IVF-ET. Zhonghua Nan Ke Xue 2010, 16:897-900.

10. Guzick DS, Overstreet JW, Factor-Litvak P, Brazil CK, Nakajima ST, Coutifaris C, Carson SA, Cisneros P, Steinkampf MP, Hill JA, Xu D, Vogel DL, National Cooperative Reproductive Medicine Network: Sperm morphology, motility, and concentration in fertile and infertile men. $N$ Engl J Med 2001, 345:1388-1393.

11. Perdrix A, Saïdi R, Ménard JF, Gruel E, Milazzo JP, Macé B, Rives N: Relationship between conventional sperm parameters and motile sperm organelle morphology examination (MSOME). Int J Androl 2012, 35:491-498.

12. Karabulut $A$, Tekin A: Alterations in the morphology and motility of spermatozoa: relation with total sperm count. Pam Med J 2013, 6:1-4.

13. Said TM, Agarwal A, Sharma RK, Mascha E, Sikka SC, Thomas AJ Jr: Human sperm superoxide anion generation and correlation with semen quality in patients with male infertility. Fertil Steril 2004, 82:871-877.

14. Cocuzza M, Sikka SC, Athayde KS, Agarwal A: Clinical relevance of oxidative stress and sperm chromatin damage in male infertility: an evidence based analysis. Int Braz J Urol 2007, 33:603-621.

15. Platts AE, Dix DJ, Chemes HE, Thompson KE, Goodrich R, Rockett JC, Rawe W, Quintana S, Diamond MP, Strader LF, Krawetz SA: Success and failure in human spermatogenesis as revealed by teratozoospermic RNAs. Hum Mol Genet 2007, 16:763-773.

16. Venkatesh S, Singh MPG, Gupta NP, Deecaraman M, Dada R: Correlation of sperm morphology and oxidative stress in infertile men. Iran J Reprod Med 2009, 1:29-34.

17. Saleh RA, Agarwal A, Kandirali E, Sharma RK, Thomas AJ, Nada EA, Evenson $D P$, Alvarez JG: Leukocytospermia is associated with increased reactive oxygen species production by human spermatozoa. Fertil Steril 2002, 78:1215-1224.

18. Oborna I, Fingerova H, Novotny J, Brezinova J, Svobodova M, Aziz N: Reactive oxygen species in human semen in relation to leukocyte contamination. Biomed Pap Med Fac Univ Palacky Olomouc Czech Repub 2009, 153:53-57

19. Aitken RJ, Jones KT, Robertson SA: Reactive oxygen species and sperm function-in sickness and in health. J Androl 2012, 33:1096-1106.

20. Colagar AH, Karimi F, Jorsaraei SGA: Correlation of sperm parameters with semen lipid peroxidation and total antioxidants levels in astheno- and oligoastheno- teratospermic men. Iran Red Cresc Med J 2013, 15:e6409-e6414

21. Aziz N, Saleh RA, Sharma RK, Lewis-Jones I, Esfandiari N, Thomas AJ Jr, Agarwal A: Novel association between sperm reactive oxygen species production, sperm morphological defects, and the sperm deformity index. Fertil Steril 2004, 81:349-354.

22. Pasqualotto FF, Sharma RK, Pasqualotto EB, Agarwal A: Poor semen quality and ROS-TAC scores in patients with idiopathic infertility. Urol Int 2008, $81: 263-270$

23. World Health Organization: WHO Laboratory Manual for the Examination and Processing of Human Semen. 5th edition. Geneva, Switzerland: World Health Organization; 2010.

24. Kashou AH, Sharma R, Agarwal A: Assessment of oxidative stress in sperm and semen. Methods Mol Biol 2013, 927:351-361.
25. Krausz C, Giachini C: Genetic risk factors in male infertility. Arch Androl 2007, 53:125-133.

26. Haidl G, Hartmann R, Hofmann R: Morphologic studies of spermatozoa in disorders of motility. Andrologia 1987, 19:433-447.

27. Szczygiel M, Kurpisz M: Teratozoospermia and its effect on male fertility potential. Andrologia 1999, 31:63-75.

28. Khan MS, Ali I, Khattak AM, Ullah A, Khan MA, Javed A: Frequency of polyzoospermia and teratozoospermia in infertile men. Gomal J Med Sci 2006, 4:10-14.

29. Nikbakht $R$, Saharkhiz N: The influence of sperm morphology, total motile sperm count of semen and the number of motile sperm inseminated in sperm samples on the success of intrauterine insemination. Inter J Fertil Steril 2011, 5:168-173.

30. Chocat A, Creveuil C, Galeraud-Denis I, Herlicoviez D, Herlicoviez M, Sauvalle A: Valeur prédictive des parameters spermatiques non automatisés et des parametres cinétiques automatisés sur le taux de clivage en fécondation in vitro. Gynecol Obstet Fertil 2001, 29:301-307.

31. Pisarska MD, Casson PR, Cisneros PL, Lamb DJ, Lipshultz LI, Buster JE, Carson SA: Fertilization after standard in vitro fertilization versus intracytoplasmic sperm injection in subfertile males using sibling oocytes. Fertil Steril 1999, 71:627-632.

32. El-Tohamy MM: The mechanisms by which oxidative stress and free radical damage produces male infertility. Life Sci J 2012, 9:674-688.

33. Aitken RJ, Curry BJ: Redox regulation of human sperm function: from the physiological control of sperm capacitation to the etiology of infertility and DNA damage in the germ line. Antioxid Redox Signal 2011, 14:367-381.

34. Gil-Guzman E, Ollero M, Lopez MC, Sharma RK, Alvarez JG, Thomas AJ Jr, Agarwal A: Differential production of reactive oxygen species by subsets of human spermatozoa at different stages of maturation. Hum Reprod 2001, 16:1922-1930.

35. Tirado Sanchez EE, Marquette ML, Brown DB, Ansari NH: The effect of oxidative stress on human sperm morphology. Fertil Steril 2006, 86:S444.

36. Rengan AK, Agarwal A, van der Linde M, du Plessis SS: An investigation of excess residual cytoplasm in human spermatozoa and its distinction from the cytoplasmic droplet. Reprod Biol Endocrinol 2012, 10:92-99.

37. Cooper TG: The epididymis, cytoplasmic droplets and male fertility. Asian J Androl 2011, 13:130-138.

38. Huszar G, Vigue L: Correlation between the rate of lipid peroxidation and cellular maturity as measured by creatine kinase activity in human spermatozoa. J Androl 1994, 15:71-77.

39. Gomez E, Buckingham DW, Brindle J, Lanzafama F, Irvine DS, Aitken RJ: Development of an image analysis system to monitor the retention of residual cytoplasm by human spermatozoa: correlation with biochemical markers of the cytoplasmic space, oxidative stress, and sperm function. J Androl 1996, 17:276-287.

40. Dandekar SP, Parkar GM: Correlation between creatine kinase activity, lipid-peroxidation and water test in male infertility. J Postgrad Med 1999, 45:42-48.

41. Fraczek M, Sanocka D, Kamieniczna M, Kurpisz M: Proinflammatory cytokines as an intermediate factor enhancing lipid sperm membrane peroxidation in in vitro conditions. J Androl 2008, 29:85-92.

42. Ghani E, Keshtgar S, Habibagahi M, Ghannadi A, Kazeroni M: Expression of NOX5 in human teratozoospermia compared to normozoospermia. Andrologia 2013, 45:351-356.

43. Whittington K, Harrison SC, Williams KM, Day JL, McLaughlin EA, Hull MG, Ford WC: Reactive oxygen species (ROS) production and the outcome of diagnostic tests of sperm function. Int J Androl 1999, 22:236-242.

44. Desai NR, Mahfouz R, Sharma R, Gupta S, Agarwal A: Reactive oxygen species levels are independent of sperm concentration, motility, and abstinence in a normal, healthy, proven fertile man: a longitudinal study. Fertil Steril 2010, 94:1541-1543.

45. Ombelet W, Bosmans E, Janssen M, Cox A, Vlasselaer J, Gyselaers W, Vandeput $H$, Gielen J, Pollet H, Maes M, Steeno O, Kruger T: Semen parameters in a fertile versus subfertile population: A need for change in the interpretation of semen testing. Hum Reprod 1997, 12:987-993.

46. Günalp S, Onculoglu C, Gürgan T, Kruger TF, Lombard CJ: A study of semen parameters with emphasis on sperm morphology in a fertile population: An attempt to develop clinical thresholds. Hum Reprod 2001, 16:110-114.

47. Menkveld R, Wong WY, Lombard CJ, Wetzels AM, Thomas CM, Merkus HM, Steegers-Theunissen RP: Semen parameters, including WHO and strict 
criteria morphology, in a fertile and infertile population: An effort towards standardization of in vivo thresholds. Hum Reprod 2001, 16:1165-1171.

48. Guzick DS, Overstreet JW, Factor-Litvak P, Brazil CK, Nakajima ST, Coutifaris C, Carson SA, Cisneros P, Steinkampf MP, Hill JA, Xu D, Vogel DL, National Cooperative Reproductive Medicine Network: I: Sperm morphology, motility, and concentration in fertile and infertile men. N Engl J Med 2001, 345:1388-1393.

49. Allamanenei SRS, Agarwal A, Nallella KR, Sharma RK, Thomas AJ Jr, Sikka SC: Characterization of oxidative stress status by evaluation of reactive oxygen species levels in whole semen and isolated spermatozoa. Fertil Steril 2005, 83:800-803.

50. Desai N, Sharma RK, Makker K, Sabanegh E, Agarwal A: Physiologic and pathologic levels of reactive oxygen species in neat semen of infertile men. Fertil Steril 2009, 92:1626-1631.

51. Benjamin D, Sharma RK, Moazzam A, Agarwal A: Methods for the detection of ROS in human sperm samples. In Studies on Men's Health and Fertility. Edited by Agarwal A, Aitken RJ, Alvarez JG. New York: Springer Science + Business Media; 2012:257-274.

doi:10.1186/1477-7827-12-45

Cite this article as: Agarwal et al:: Relationship amongst teratozoospermia, seminal oxidative stress and male infertility. Reproductive Biology and Endocrinology 2014 12:45.

\section{Submit your next manuscript to BioMed Central and take full advantage of:}

- Convenient online submission

- Thorough peer review

- No space constraints or color figure charges

- Immediate publication on acceptance

- Inclusion in PubMed, CAS, Scopus and Google Scholar

- Research which is freely available for redistribution 